\title{
When in doubt, ask the audience: Potential users' perceptions of Internet-delivered cognitive behavioural therapy for chronic pain
}

\author{
Luke H Schneider MA, Heather D Hadjistavropoulos PhD
}

\begin{abstract}
LH Schneider, HD Hadjistavropoulos. When in doubt, ask the audience: Potential users' perceptions of Internet-delivered cognitive behavioural therapy for chronic pain. Pain Res Manag 2014;19(4):173-178.
\end{abstract}

BACKGROUND: Although research has demonstrated that Internetdelivered cognitive behavioural therapy (ICBT) for chronic pain helps with adjustment to pain, it remains unclear how this treatment option would initially be perceived by individuals with chronic pain.

OBJECTIVES: To explore initial perceptions of ICBT and to examine variables that correlate with an expressed interest in ICBT as a treatment option among individuals with chronic pain.

METHODS: A total of 129 individuals with chronic pain completed a survey assessing perceptions of ICBT and individual difference variables that could be correlated with expressed interest in ICBT (eg, demographic characteristics, pain, computer self-efficacy).

RESULTS: Results showed that most participants perceived ICBT as a potentially valuable service with multiple benefits. Being female, having greater pain severity and interference, and having greater computer selfefficacy and lower computer anxiety were positively correlated with interest in receiving ICBT.

CONCLUSIONS: Combined with previous research on treatment efficacy of ICBT for chronic pain, the results should serve to stimulate further research on integrating ICBT within existing health care services.

Key Words: Chronic pain; Internet cognitive behavioural therapy

$\mathrm{C}$ ompared with the general population, individuals with chronic pain are at increased risk for developing psychological conditions such as depression and anxiety disorders (1). One common treatment for individuals with chronic pain is cognitive behavioural therapy (CBT), which has been shown to effectively reduce pain severity, disability, depression and anxiety across various chronic pain conditions (2). Despite these benefits, CBT is not readily available to individuals with chronic pain within the Canadian health care system (3). Internetdelivered CBT (ICBT) has emerged as a potential method of improving access to CBT for chronic pain (4). In ICBT, structured therapeutic content, typically divided into weekly lessons, is delivered over the Internet and participants work on offline tasks to facilitate learning. ICBT can be therapist-assisted through secure messaging or telephone calls, or can be entirely self-directed. ICBT has several benefits such as improved access and convenience for users, greater privacy, and the potential to reduce waiting times and operating costs (5-7).

The efficacy of ICBT for reducing chronic pain has been examined in various contexts outside of Canada among users experiencing a number of different chronic pain conditions such as back pain, headache and mixed pain conditions (reviewed by Macea et al [4]). A recent meta-analysis of studies investigating ICBT for chronic pain reported an effect size of $\mathrm{d}=0.285$ for the reduction of pain among those receiving ICBT compared with control groups (4). Studies also show that ICBT is associated with improved mood, anxiety and functioning compared with waiting list groups $(8,9)$.

\author{
Dans le doute, demandez à l'auditoire : les \\ perceptions des utilisateurs potentiels d'une \\ thérapie cognitivo-comportementale par Internet \\ pour soigner la douleur chronique
}

HISTORIQUE : Même si la recherche a démontré que la thérapie
cognitivo-comportementale par Internet (TCCI) contribue à s'adapter à la
douleur chronique, on ne sait pas quelle serait la perception initiale des per-
sonnes souffrant de douleurs chroniques envers cette option thérapeutique.
OBJECTIFS : Explorer les perceptions initiales de la TCCI et examiner
les variables corrélées avec un intérêt exprimé envers la TCCI comme
option thérapeutique chez les personnes souffrant de douleurs chroniques.
MÉTHODOLOGIE : Au total, 129 personnes souffrant de douleur chro-
nique ont rempli un sondage évaluant les perceptions envers la TCCI ainsi
que les variables individuelles qui pouvaient être corrélées avec un intérêt
exprimé envers la TCCI (p. ex., caractéristiques démographiques, douleur,
aisance à l'ordinateur).
RÉSULTATS : Les résultats ont démontré que la plupart des participants
percevaient la TCCI comme un service au potentiel intéressant comportant
de multiples avantages. Être de sexe féminin, souffrir de douleurs plus intenses
ou d'interférences plus importantes causées par la douleur, une plus grande
aisance à l'ordinateur et une anxiété plus faible vis-à-vis de l'ordinateur
avaient une corrélation positive avec l'intérêt à recevoir une TCCI.
CONCLUSIONS : Une fois combinés à des recherches antérieures sur
l'efficacité thérapeutique de la TCCI à l'égard de la douleur chronique, les
résultats devraient stimuler des recherches plus approfondies sur
l'intégration de la TCCI aux services de santé en place.

To our knowledge, ICBT for chronic pain is not currently being offered in Canada. Before integration of such a program within existing health care services, researchers have suggested it is important to understand pre-existing perceptions that individuals with chronic pain hold toward ICBT $(4,9)$. This research direction is consistent with the values of the Canadian Institutes of Health Research, which recommends engaging citizens before implementing new programs (10). These preexisting perceptions have the potential to influence whether individuals would consider ICBT as a potential treatment option.

Previous research has examined perceptions of Internet-based interventions for a variety of conditions including chronic pain. In nonpain samples, interest in Internet-based treatment has been found to be lower than interest in face-to-face services (11-13). For example, Carper et al (13) reported that a treatment-seeking group of patients with depressive and anxiety disorders expressed little desire to use computerized CBT compared with face-to-face treatment. Research examining perceptions of Internet-based interventions for chronic pain, however, has revealed that potential users often hold favourable attitudes toward these interventions (14-16). For example, Stinson et al (15) reported that a sample of 17 young adults participating in a needs assessment believed that an Internet-based program would meet their needs and had the potential to overcome treatment barriers. Additionally, Huguet et al (14) reported that a sample of 25 headache sufferers expressed favourable attitudes toward using a smartphonedelivered headache intervention. 
Although previous research has explored potential users' initial perceptions toward Internet-delivered services for chronic pain, often these studies ask about the acceptability of these interventions as a part of a focus group or after participants have experienced the intervention first-hand. Having first-hand experience either using or helping to design these interventions could increase participants' familiarity with these interventions and contribute to the positive perceptions observed. As such, to understand interest in and likely use of ICBT by individuals with chronic pain, it is important to explore initial perceptions of ICBT when participants are provided a basic description of ICBT for chronic pain. This is important to study because such initial perceptions may be a significant barrier in treatment uptake.

As a component of understanding initial perceptions toward ICBT for chronic pain, it is also important to identify factors that may be related to these perceptions. Currently, there is evidence that implicates condition severity $(17,18)$ and participant sex $(4,19,20)$ as factors that influence drop-out from ICBT for chronic pain. More specifically, males and individuals with greater pain severity are found to be more likely to discontinue participation in ICBT for chronic pain. As such, these two variables may also be predictive of initial interest in ICBT for chronic pain.

Additionally, computer-related attitudes, such as computer selfefficacy and computer anxiety, may influence potential users' interest in ICBT. Computer self-efficacy refers to one's perceived ability to accomplish various computer tasks $(21)$ and is associated with more frequent technology use (22). Computer anxiety is defined as the level of fear/apprehension one feels when considering using a computer and is associated with general avoidance of or excessive caution using computers (23).

In Canada, there appears to be a need for more accessible and timely psychological interventions to treat individuals with chronic pain (24) and evidence supports the efficacy of ICBT for chronic pain $(4,8)$. Before ICBT for chronic pain is formally integrated into the Canadian health care system, there needs to be evidence that this treatment is attractive to individuals with chronic pain. Although studies have explored perceptions toward ICBT programs in general, there has not been a specific investigation of potential users' initial perceptions of ICBT for chronic pain.

The purpose of the present study was threefold: to understand initial perceptions of ICBT by individuals experiencing chronic pain; to examine potential users' interest in ICBT if it were available; and to determine whether interest in receiving ICBT is related to various demographic variables, pain severity and interference, as well as computer self-efficacy and computer anxiety. We anticipated that the findings would provide beneficial information that could assist with future attempts to deliver ICBT for chronic pain.

\section{METHODS}

\section{Participants}

Criteria for inclusion to complete the online survey were: $\geq 18$ years of age; Canadian citizens; self-reported chronic pain condition in at least one site in the body lasting $\geq 6$ months; self-reported seeking or undergoing medical treatment for chronic pain; and ability to complete questionnaires online (ie, computer and Internet access) in English. Because ICBT can be used in multiple contexts (eg, primary care or tertiary care, self-referral or provider referral) participants were recruited using multiple strategies including online advertisements listed on local classifieds (eg, Kijiji), social media sites (eg, Facebook, Twitter), health care-related discussion groups (eg, SomaSimple, Google Groups) and pain-related organizations (eg, Arthritis Society). Participants were also recruited from waiting rooms of local medical walk-in clinics and rehabilitation centres using poster advertisements.

The survey was accessed by 185 individuals, with 129 participants (69.7\%) completing the entire survey. The remainder of the participants terminated the survey prematurely without completing essential sections (ie, ICBT perception questions) and were, therefore, excluded.
Reflecting the diverse recruitment strategies, participants reported that they learned about the study through online classified advertisements/social media $(n=41[32 \%])$, friends/family $(n=40$ [31\%]), online discussion groups/pain management organizations $(n=35[27 \%])$ and walk-in clinics/rehabilitation centres $(n=13[10 \%])$.

The mean $( \pm$ SD) age of participants was $47.10 \pm 12.17$ years, and the majority of participants were female $(n=106$ [82\%]) and Caucasian $(n=117$ [91\%]). Pain was reported in multiple areas of the body $(5.95 \pm 4.07)$ with the most frequently cited areas being the back $(n=95[74 \%])$, lower leg/foot $(n=84[65 \%])$, arm/hand $(n=71[55 \%])$, shoulder $(n=67[52 \%])$, hip $(n=64[50 \%])$, head $(n=43[33 \%])$, jaw $(n=34[26 \%])$, visceral $(n=25[19 \%])$ and chest $(n=24[19 \%])$. The mean response indicated that participants had experienced pain for approximately $12 \pm 9.43$ years. Pain severity $(5.56 \pm 1.79)$ and interference scores $(6.12 \pm 2.19)$ on the Brief Pain Inventory were moderate.

The majority of respondents were located in Alberta $(n=32[25 \%])$, Saskatchewan $(n=30[23 \%])$ and Ontario $(n=29[22 \%])$, and approximately one-half of the respondents reported that they were from a city with a population $>200,000(n=70[54 \%])$. A majority of participants stated that they had either received a college certificate/some university $(n=52[40 \%])$ or had received a bachelor's degree $(n=31[24 \%])$ and indicated that they were either working full-time $(n=48[37 \%])$ or were on disability leave related to chronic pain $(n=46[36 \%])$.

Using a seven-point Likert scale ranging from 1 (no knowledge) to 7 (extensive knowledge), participants described moderate knowledge of psychological pain management techniques $(4.2 \pm 2.02)$ and CBT (3.56 \pm 2.12$)$, but low knowledge of ICBT $(2.44 \pm 1.66)$. A considerable number of respondents had received psychological therapy in the past $(n=79[61 \%])$, although therapy was not limited to issues involving chronic pain. A minority of participants $(n=23[18 \%])$ reported having received CBT for chronic pain.

\section{Procedure}

Individuals who were interested in participating contacted the primary researcher, who sent a link to study materials. This link presented participants with a consent form and then a description of ICBT derived from reviewing previous research in this area (see Table 1 for details). The brief description of ICBT was prepared to inform participants about the nature of ICBT, why it may be useful for individuals with chronic pain, how it is typically delivered and who may not be appropriate for ICBT. Given the heterogeneity reported among ICBT programs (4) and the lack of a specific ICBT program for adults with chronic pain available to Canadians, a general summary of ICBT program features was provided to participants derived from a review of ICBT for chronic pain (4). This approach enabled the examination of general perceptions of ICBT, rather than exploring perceptions associated with a specific ICBT program. The ICBT description was reviewed and revised several times following input by the research group and a small convenience sample of participants. The reading level was estimated to be grade 9 to 10 (25).

After reading the ICBT information document, participants completed the survey questions described below. The questions were based on researcher-generated items and previous studies assessing the adoption of technology-based interventions (26), the general principles of technology acceptance models (27) and the dimensions of health care service (28). Items were also generated from interviews with 11 participants who were recruited through convenience sampling to participate in telephone interviews. The telephone interview asked participants about their perceptions of ICBT. These interviews were transcribed verbatim using NVivo, a qualitative transcription tool, and perceptions of the strengths and limitations of ICBT were identified using thematic content analysis (29). These perceptions were then cross-referenced with items that had been generated previously and served as a method of confirming that the survey captured important aspects of ICBT; of note, two unique survey items were generated from these interviews (eg, ICBT for chronic pain would help people learn to manage chronic pain; people would gain a better understanding of 
TABLE 1

Summary of content shared about Internet-delivered cognitive behavioural therapy (ICBT)

\section{What is ICBT:}

1. ICBT stands for Internet-delivered cognitive behavioural therapy

2. ICBT treatment can be designed to help people manage chronic pain

3. One of the main parts of ICBT for chronic pain is helping clients learn various coping skills for managing chronic pain

4. Users are often taught relaxation strategies and how to plan and engage in activities when faced with chronic pain

5. Users are also taught how to identify and challenge thinking patterns that may contribute to low mood or low quality of life

6. These strategies are intended to increase quality of life as well as stress management

II. Why ICBT for chronic pain:

1. Chronic pain is an important area of study because of the high number of people affected by chronic pain

2. Approximately $15 \%$ to $18 \%$ of Canadians will develop a chronic pain condition during their lifetime. People with chronic pain often find they need to learn new ways to manage their pain and often have difficulty obtaining help with this

III. How does it work:

1. There are many types of ICBT programs

2. Most programs deliver content in sections which allow users to review program material on a daily basis

3. Users typically receive a login name and a password which allows them to access the program

4. Users can login to the program as often as they like to review program material

5. Users can also have contact with a trained provider, most commonly a psychologist or someone under the supervision of a psychologist

6. Messages are often sent online through a private and secure messaging system

IV. Who can use it:

1. ICBT may not be appropriate for people who are at risk of harming themselves or others, people experiencing suicidal thoughts, manic symptoms or delusions, and people who are misusing drugs or alcohol

2. These people would benefit most from in-person treatment and they would not be appropriate for ICBT

their pain if they received ICBT). For each participant who completed the survey, $\$ 1$ was donated to the Canadian Pain Foundation and every 10 th person who completed the survey was mailed a free copy of a mindfulness-based chronic pain management book.

\section{Measures}

Background information: Demographic questions included: age, sex, ethnicity, employment status, education level, province of residence and the size of the community where participants resided. Participants were also asked to specify the location and nature of their chronic pain condition. Additional information was gathered from participants regarding their familiarity with CBT and knowledge of ICBT and psychological pain management techniques using a scale that ranged from 1 (no knowledge) to 7 (extensive knowledge). Additional questions inquired whether participants had received therapy in the past and, specifically, whether they had ever received CBT for pain management.

Brief Pain Inventory: Participants completed the Brief Pain Inventory-Short Form to assess pain severity and pain-related interference. The measure has strong psychometric properties across multiple pain conditions (30).

Initial ICBT perceptions: Participants rated their level of agreement or disagreement with 20 statements about ICBT using a Likert scale that ranged from 1 (strongly disagree) to 7 (strongly agree). Questions assessed strengths and limitations of ICBT in general, strengths and limitations of ICBT for chronic pain, perceptions of the therapeutic relationship in ICBT, and perceptions about information security in ICBT. Additionally, one question asked participants how likely they would be to use ICBT for chronic pain if it were available.

Computer self-efficacy: A 10-item computer self-efficacy measure (21) asked participants to rate their confidence using an unfamiliar computer program under various conditions (eg, if I had a manual, if there was someone around to help). If individuals endorsed being able to use the program, ratings were made using a 1 (not at all confident) to 10 (totally confident) scale. This scale has strong psychometric properties $(21,31)$. Computer Anxiety Rating Scale: Computer anxiety was measured using the 19-item Computer Anxiety Rating Scale (32), which assesses anxiety about interacting with computers and computer technology. Participants rated their level of agreement on a 1 (strongly disagree) to 5 (strongly agree) scale. The Computer Anxiety Rating Scale has been found to be a reliable and valid measure (33).
Data analysis

Means, SDs and frequencies were used to examine ICBT perception statements and participant interest in using ICBT if it were available. Because ratings were made on a 1 (strongly disagree) to 7 (strongly agree) scale, statements that were rated $>5$ were interpreted as showing general agreement with the statement and statements that were rated $<3$ were interpreted as showing general disagreement with the statement. Pearson correlations were conducted to test for statistically significant correlations between interest in using ICBT and continuous variables (eg, pain severity, computer anxiety), while a point biserial correlation was used to test for a statistically significant correlation between interest in using ICBT and participant sex (men were coded as 0 ; women were coded as 1 ). The sample size was determined to allow for sufficient power to examine the planned number of correlations between interest in ICBT and demographic variables, pain severity and interference, as well as computer self-efficacy and computer anxiety. In total, 10 correlations were examined; given the sample size, risk of type I error was minimal.

\section{RESULTS}

General ICBT benefits and limitations

Examination of mean responses indicated that participants agreed that ICBT was important for patients in rural areas $(5.65 \pm 1.47)$, for those who have mobility issues $(5.67 \pm 1.42)$ and for those who have a difficult time attending appointments $(5.60 \pm 1.48)$. On average, participants also agreed that ICBT provides greater anonymity compared with face-to-face treatment $(5.21 \pm 1.38)$. The mean response to ICBT limitation statements indicated that participants generally disagreed with the statement that ICBT would be difficult to understand $(2.95 \pm 1.42)$. Participants gave more neutral ratings to statements that ICBT may give rise to misunderstandings $(3.57 \pm 1.52)$ and would be an impersonal form of treatment $(3.46 \pm 1.82)$.

\section{Specific ICBT benefits and limitations}

Participants agreed that ICBT would be a convenient $(5.64 \pm 1.21)$ and efficient $(5.43 \pm 1.42)$ way to learn to manage chronic pain. They gave more neutral ratings to statements that ICBT would help people to learn to manage their pain $(4.67 \pm 1.24)$ and that people would gain a better understanding of their pain $(4.83 \pm 1.25)$. Participants disagreed that it would be difficult to learn how to manage chronic pain over the 


\begin{tabular}{lc}
$\begin{array}{l}\text { TABLE } 2 \\
\text { Correlations between interest in using Internet-delivered } \\
\text { cognitive behavioural therapy and individual } \\
\text { characteristics }\end{array}$ \\
\hline Variable & $\mathbf{r}$ \\
\hline Age & -0.13 \\
Sex (male = 0, female =1) & $0.24^{*}$ \\
Chronic pain duration & 0.05 \\
Medical condition & -0.04 \\
Number of pain areas & 0.04 \\
Number of medical conditions & -0.03 \\
Computer self-efficacy & $0.20^{*}$ \\
Computer anxiety & $-0.34^{* *}$ \\
Pain severity & $0.23^{*}$ \\
Pain interference & $0.26^{* *}$ \\
\hline
\end{tabular}

${ }^{*} P<0.05 ;{ }^{* *} P<0.01$

Internet (2.98 \pm 1.46$)$, that it would be unacceptable to offer treatment over the Internet $(2.15 \pm 1.30)$ or that there is ample information about chronic pain available on the Internet $(1.99 \pm 1.15)$.

\section{Therapeutic relationship perceptions}

Respondents generally believed it would be easy to express their thoughts and feelings to $(5.09 \pm 1.59)$, that they could develop an open and honest relationship with $(5.11 \pm 1.44)$ and that they would feel supported and encouraged by $(4.96 \pm 1.31)$ a trained ICBT provider.

\section{Information security perceptions}

Participants agreed with the statement that a trained ICBT provider would keep their personal information secure $(5.13 \pm 1.40)$. They provided a more neutral rating for the statement that they would worry about the security of their personal information in ICBT $(3.53 \pm 1.94)$.

\section{Interest in using ICBT}

Examination of interest in future use of ICBT for chronic pain, if such a program were available, suggested that participants were likely to use ICBT in the future $(5.53 \pm 1.45)$. Correlation analyses examining the association between interest in using ICBT and participant variables (Table 2 ) revealed that women (coded as 1 ) expressed greater interest in using ICBT than men (coded as $0 ; \mathrm{r}=0.24 ; \mathrm{P}=0.01$ ). Interest in using ICBT was also related to computer self-efficacy $(r=0.20 ; P=0.02)$ and computer anxiety $(\mathrm{r}=-0.34 ; \mathrm{P}<0.01)$, indicating that higher computer self-efficacy and lower computer anxiety were associated with increased interest in using ICBT. Pain severity $(r=0.23 ; \mathrm{P}=0.01)$ and pain interference $(r=0.26 ; \mathrm{P}<0.01)$ both correlated with interest in using ICBT. Conversely, ICBT interest was not related to participant age $(r=-0.13$; $\mathrm{P}=0.14)$, number of pain areas $(\mathrm{r}=0.04 ; \mathrm{P}=0.67)$, chronic pain duration $(r=0.05 ; \mathrm{P}=0.55)$, the presence of another medical condition $(r=-0.04$; $\mathrm{P}=0.65)$ or number of medical conditions $(\mathrm{r}=-0.03 ; \mathrm{P}=0.75)$.

\section{DISCUSSION}

In Canada, there is a need for timely and accessible psychological resources for chronic pain management. Evidence indicates that ICBT is a potentially valuable service because individuals who participate in ICBT report reduced pain levels and improvements in mood, anxiety and functioning $(4,8,9)$. Relatively little is known about potential users' initial perceptions toward this mode of delivery. Consistent with the principles of citizen engagement (10), the results of the present study incrementally advance the literature by examining initial perceptions of ICBT among individuals with chronic pain briefly introduced to ICBT.

The results demonstrated that potential users had little preexisting knowledge of ICBT but, once informed of this treatment option, formed a positive impression of the service. Specifically, participants believed there were many potential benefits of ICBT, both as a general form of treatment and as a treatment option for chronic pain.
Participants also endorsed statements to suggest that they could form a relationship with a therapist online and trust a therapist to keep their information secure. Most significantly, they expressed an interest in participating in this form of treatment if it were made available to them. Collectively, the responses suggest that participants regarded ICBT as an acceptable form of treatment. Combined with past research showing the efficacy of ICBT for chronic pain, the current results suggest that ICBT has the potential to enhance access to CBT for chronic pain and that further research devoted to exploring the integration of ICBT within existing health care services would be valuable.

In the present study, participants had no strong objections to ICBT, but some items received neutral ratings. These items may represent areas where participants were hesitant about ICBT. Providing educational material targeting such areas may help potential participants to better understand the research surrounding ICBT (eg, evidence for how ICBT can be used to improve pain and mood) and how communication occurs and can be facilitated during the course of ICBT, which would help them to make more informed decisions about ICBT. Specifically, we may need to present potential participants with information about the ICBT communication process, the research evidence for ICBT, and about how their personal information will be safeguarded in ICBT.

Despite some neutral ratings, the generally favourable perceptions among individuals with chronic pain were surprising given that past researchers have found that patients prefer face-to-face therapy in comparison with Internet-delivered treatment (11-13). This previous research, however, may have been biased in that perceptions of Internet-delivered treatment were not examined independent of face-to-face therapy. In the present research, we did not ask about preference for face-to-face therapy because our interest was in exploring openness to ICBT alone in light of challenges patients face accessing services. In general, the favourable perceptions of ICBT were consistent with perceptions of ICBT after individuals have had more extensive experience or opportunity to learn about ICBT (14-16).

In the present study, interest in using ICBT was greater among women than men. This finding appears to be consistent with research showing that men generally have more negative attitudes toward helpseeking and receiving therapy than women (34). Pain severity and pain interference were both correlated with interest in using ICBT, while pain duration was not. It is possible that the degree of pain severity and disability serve to motivate interest in treatment, more so than the length of time experiencing pain. Interestingly, while pain severity may serve as a motivator to seek out treatment, it has also been found to be a predictor of lower likelihood of completing ICBT $(17,18)$. Higher computer self-efficacy and lower computer anxiety were correlated with endorsement of interest in ICBT. This is not the first time computer self-efficacy or computer anxiety have been identified as important constructs in technology adoption $(31,35)$. These findings highlight the need for clinicians to consider assessing computer selfefficacy and computer anxiety before referral to ICBT.

While several variables were positively correlated with interest in using ICBT, several background variables (eg, age, pain duration) were not correlated with interest in using ICBT. Future research will need to identify additional variables that may influence perceptions of ICBT, and also examine whether these same variables predict actual participation and engagement in ICBT within community settings.

\section{Limitations and future directions}

One potential limitation to the present study was that participants selfreferred to participate. This chronic pain sample may have been actively seeking novel forms of treatment, thus limiting finding generalizability. Given that most participants learned of the study largely through the Internet, participants may have had an overly favourable perception of ICBT compared with individuals generally residing in the community. It 
is also likely that online recruiting resulted in self-selected participants who had low computer anxiety and high computer self-efficacy levels. An important next step would be to explore perceptions of ICBT in a sample randomly selected from a chronic pain setting. Although the online recruitment may be a limitation to the present study, it is important to highlight that a report by the Canadian Internet Registration Authority (36) indicated that Canadians are the heaviest users of the Internet in the world. Additionally, the 2012 Canadian Internet Use Survey (37) found that $80 \%$ of Canadian households had Internet access at home and that medical/health-related searches rank fifth among the top reasons Canadians use the Internet. This would suggest that the online sample may not be considerably different from a sample recruited from a chronic pain setting.

It is also important to note that while the sample was limited to online participants who self-referred to participate, this represents an important group of potential users who would foreseeably access ICBT in the future and, thus, are important to study. Consistent with the background characteristics of our sample, a review of ICBT research studies for chronic pain found that the majority of ICBT users were older (ie, $>40$ years of age) and more likely to be women (4). Additionally, a study examining the prevalence rates of chronic pain in Canada found that women and older adults were more likely to report chronic pain (38). Thus, it would appear that the findings of our study would generalize to a considerable extent to other Canadians with chronic pain who may seek ICBT.

In the present study, we focused on the relationships between interest in ICBT and a carefully selected group of variables (eg, pain severity, computer self-efficacy) based on our review of the literature. The study would be strengthened with a larger sample size that would enable further analysis of perceptions of ICBT. With a larger sample size, it would also be interesting to examine whether experience with CBT or provider referral predict greater interest in ICBT. In the future, with a larger sample, further study of perceptions of ICBT among men and women may also be warranted. The unequal distribution of men and women in the present study may have artificially inflated the sex differences observed. Although participant age was not significantly correlated with intent to use ICBT, this may have reflected a restricted age range in the sample (ie, range 18 to 75 years of age), and further study of the relationship between age and perceptions of ICBT may also be warranted.

Another limitation to the current research is that participants did not have direct experience with ICBT, and formed their impressions based on information we provided. In the present study, we opted to provide a generic description of ICBT to participants that would

\section{REFERENCES}

1. Turk DC, Swanson KS, Wilson HD. Psychological aspects of pain. In: JC Ballantyne, SM Fishman, eds. Bonica's Management of Pain. Philadelphia: Lippincott Williams \& Wilkins, 2010:74-85.

2. Eccleston C, Williams AC, Morley S. Psychological therapies for the management of chronic pain (excluding headache) in adults. Cochrane Database Syst Rev 2009;(2):CD007407.

3. Canadian Pain Society. Canadian pain strategy recommended by the Canadian Pain Society: Brief for the parliamentary committee on palliative and compassionate care. <www.canadianpainsummit2012. ca/media/4655/cpsbrieftoparliamentaryctebydrlynch101910.pdf> (Accessed February 25, 2014).

4. Macea DD, Gajos K, Calil YAD, Fregni F. The efficacy of web-based cognitive behavioral interventions for chronic pain: A systematic review and meta-analysis. J Pain 2010;11:917-29.

5. Wright, JH, Wright, AS, Albano, AM, et al. Computer-assisted cognitive therapy for depression: Maintaining efficacy while reducing therapist time. Am J Psychiatry 2005;162:1158-64.

6. Gerhards SA, de Graaf LE, Jacobs LE, et al. Economic evaluation of online computerised cognitive-behavioural therapy without support for depression in primary care: Randomised trial. Br J Psychiatry 2010;196:310-8.

7. Andersson G. The promise and pitfalls of the Internet for cognitive behavioral therapy. BMC Med 2010;8:82. apply to past ICBT programs that have been the subject of research. It is possible that individuals who were given more specific information about ICBT would form divergent impressions of ICBT. Nevertheless, we anticipate that, if offered in the community, the information provided about ICBT would provide similar content given that the information we shared was drawn from research on ICBT for chronic pain. Of specific note, the possibility of financial cost for receiving ICBT was not explicitly mentioned in the ICBT description given to participants. As such, participants may have held different perceptions toward ICBT if there was a perceived financial cost to ICBT.

Aside from examining the initial perceptions of people with chronic pain, there are other groups whose initial perceptions are important but who were not included in the present study: psychologists, nonpsychologists (eg, physicians, physiotherapists) and health care administrators. While understanding potential users' perceptions is a significant first step in identifying interest in ICBT for chronic pain in Canada, future research will need to assess perceptions of these other groups to obtain a more thorough indication of the likelihood of ICBT adoption in community settings. An additional area of enquiry among providers would be to explore recommendations for the most appropriate time and place for delivery of ICBT within the community (eg, primary or tertiary care).

\section{SUMMARY}

Consistent with our expectations, examining initial perceptions of ICBT and interest in participating in ICBT among individuals with chronic pain provided us with beneficial information that could assist with future attempts to deliver ICBT. Collectively, the information obtained suggests that individuals with chronic pain without previous experience or knowledge of ICBT had generally positive perceptions of ICBT for chronic pain and that interest in ICBT varies to some degree according to sex, pain severity/interference and computer selfefficacy/anxiety. In the future, these variables represent important factors to consider when referring individuals with chronic pain to ICBT.

DISCLOSURES AND SOURCES OF FUNDING: The authors have no conflicts of interest to declare. This work was supported by funding provided by the Canadian Institutes of Health Research (reference number 01271-000) awarded to HDH. LHS received financial support from the Canadian Institutes of Health Research Frederick Banting and Charles Best Canada Graduate Scholarship and the Bank of Montreal Fellowship for Rural and Northern Studies.
8. Eccleston C, Fisher E, Craig L, Duggan GB, Rosser BA, Keogh E. Psychological therapies (Internet-delivered) for the management of chronic pain in adults. Cochrane Database Syst Rev 2014;(2):CD010152.

9. Bender JL, Radhakrishnan A, Diorio C, Englesakis M, Jadad AR. Can pain be managed through the Internet? A systematic review of randomized controlled trials. Pain 2011;152:1740-50.

10. Canadian Institutes of Health Research. CIHR's framework for citizen engagement. < www.cihr-irsc.gc.ca/e/documents/ce_ framework_e.pdf $>$ (Accessed February 25, 2014).

11. Rochlen $\mathrm{AB}$, Beretvas SN, Zack JS. The online and face-to-face counseling attitudes scales: A validation study. Meas Eval Couns Dev 2004;37:95-111.

12. Mohr DC, Siddique J, Ho J, Duffecy J, Jin L, Fokuo JK. Interest in behavioral and psychological treatments delivered face-to-face, by telephone, and by Internet. Ann Behav Med 2010;40:89-98.

13. Carper MM, McHugh RK, Barlow DH. The dissemination of computerbased psychological treatment: A preliminary analysis of patient and clinician perceptions. Adm Policy Ment Health 2013;40:87-95.

14. Huguet A, Stinson J, Mackay B, et al. Bringing psychosocial support to headache sufferers using information and communication technology: Lessons learned from asking potential users what they want. Pain Res Manag 2014;19:e1-e8. 
15. Stinson J, White M, Isaac L, et al. Understanding the information and service needs of young adults with chronic pain: Perspectives of young adults and their providers. Clin J Pain 2013;29:600-12.

16. Moore SK, Guarino H, Acosta MC, et al. Patients as collaborators: Using focus groups and feedback sessions to develop an interactive, web-based self-management intervention for chronic pain. Pain Med 2013;14:1730-40

17. Strom L, Pettersson R, Andersson G. A controlled trial of self-help treatment of recurrent headache conducted via the Internet. J Consult Clin Psychol 2000;68:722-7.

18. Devineni T, Blanchard EB. A randomized controlled trial of an Internet-based treatment for chronic headache. Behav Res Ther 2005;43:277-92.

19. Carpenter KM, Stoner SA, Mundt JM, Stoelb B. An online selfhelp CBT intervention for chronic lower back pain. Clin J Pain 2012;28:14-22.

20. Lorig KR, Ritter PL, Laurent DD, Plant K. Internet-based chronic disease self-management: A randomized trial. Med Care 2006;44:964-71.

21. Compeau DR, Higgins CA. Computer self-efficacy: Development of a measure and initial test. Mis Quarterly 1995;19:189-211.

22. Compeau DR, Higgins CA, Huff S. Social cognitive theory and individual reactions to computing technology: A longitudinal study. Mis Quarterly 1999;23:145-58.

23. Gaudron JP, Vignoli E. Assessing computer anxiety with the interaction model of anxiety: Development and validation of the computer anxiety trait subscale. Comput Human Behav 2002;18:315-25.

24. Lynch ME. The need for a Canadian pain strategy. Pain Res Manag 2011;16:77-80.

25. Benjamin RG. Reconstructing readability: Recent developments and recommendations in the analysis of text difficulty. Educ Psychol Rev 2012;24:63-88.

26. Wootton BM, Titov N, Dear BF, Spence J, Kemp A. The acceptability of Internet-based treatment and characteristics of an adult sample with obsessive compulsive disorder: An Internet survey. PLoS One 2011;6:e20548.
27. Venkatesh V, Morris MG, Davis GB, Davis FD. User acceptance of information technology: Toward a unified view. Mis Quarterly 2003;27:425-78.

28. Canadian Institute for Health Information. Learning from the best: Benchmarking Canada's health system. < https://secure.cihi.ca/free_ products/learning_from_thebest_en.pdf> (Accessed February 25, 2014).

29. Hsieh HF, Shannon SE. Three approaches to qualitative content analysis. Qual Health Res 2005;15:1277-88.

30. Cleeland CS. The brief pain inventory user guide. <www. mdanderson.org/education-and-research/departments-programs-andlabs/departments-and-divisions/symptom-research/symptomassessment-tools/BPI_UserGuide.pdf $>$ (Accessed February 25, 2014).

31. Wilfong JD. Computer anxiety and anger: The impact of computer use, computer experience, and self-efficacy beliefs. Comput Human Behav 2006;22:1001-11.

32. Heinssen RK, Glass CR, Knight LA. Assessing computer anxiety: Development and validation of the Computer Anxiety Rating Scale. Comput Human Behav 1987;3:49-59.

33. Chua SL, Chen DT, Wong AF. Computer anxiety and its correlates: A meta-analysis. Comput Human Behav 1999;15:609-23.

34. Berger JL, Addis ME, Green JD, Mackowiak C, Goldberg V. Men's reactions to mental health labels, forms of help-seeking, and sources of help-seeking advice. Psychol Men Masc 2012;14:433-43.

35. Saade RG, Kira D. Mediating the impact of technology usage on perceived ease of use by anxiety. Comput Educ 2007;49:1189-204.

36. Canadian Internet Registration Authority. Fact Book 2013. <www. cira.ca/factbook/2013/index.html> (Accessed February 25, 2014).

37. Statistics Canada. Canadian Internet use survey: Household file. <equinox2.uwo.ca> (Accessed February 25, 2014).

38. Reitsma ML, Tranmer JE, Buchanan DM, Vandenkerkhof EG. The prevalence of chronic pain and pain-related interference in the Canadian population from 1994 to 2008. Chronic Dis Inj Canada 2011;31:157-64. 


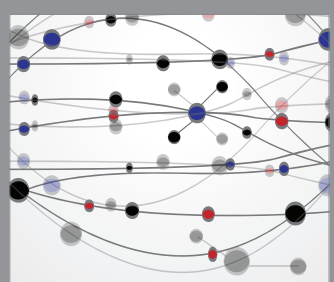

The Scientific World Journal
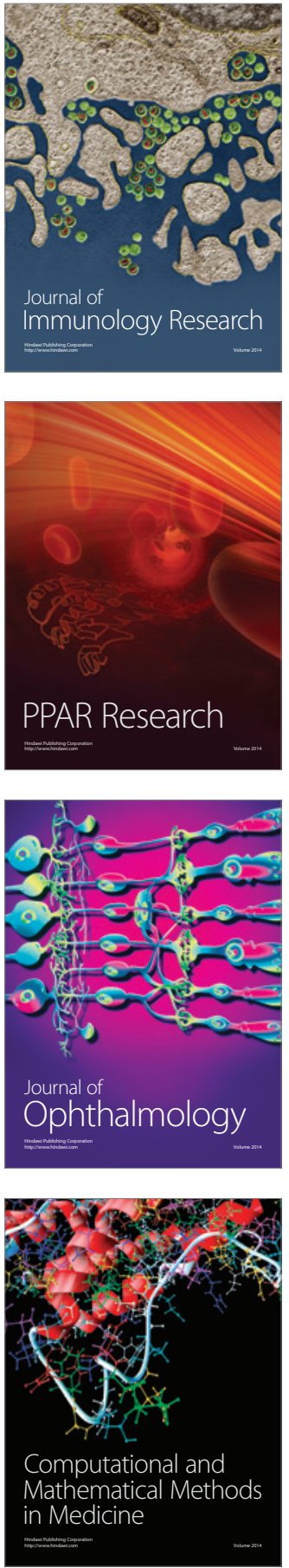

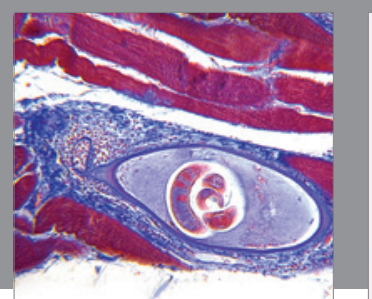

Gastroenterology Research and Practice

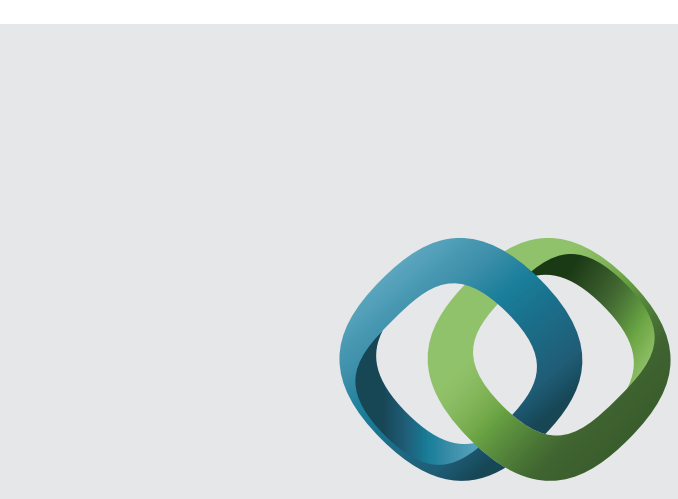

\section{Hindawi}

Submit your manuscripts at

http://www.hindawi.com
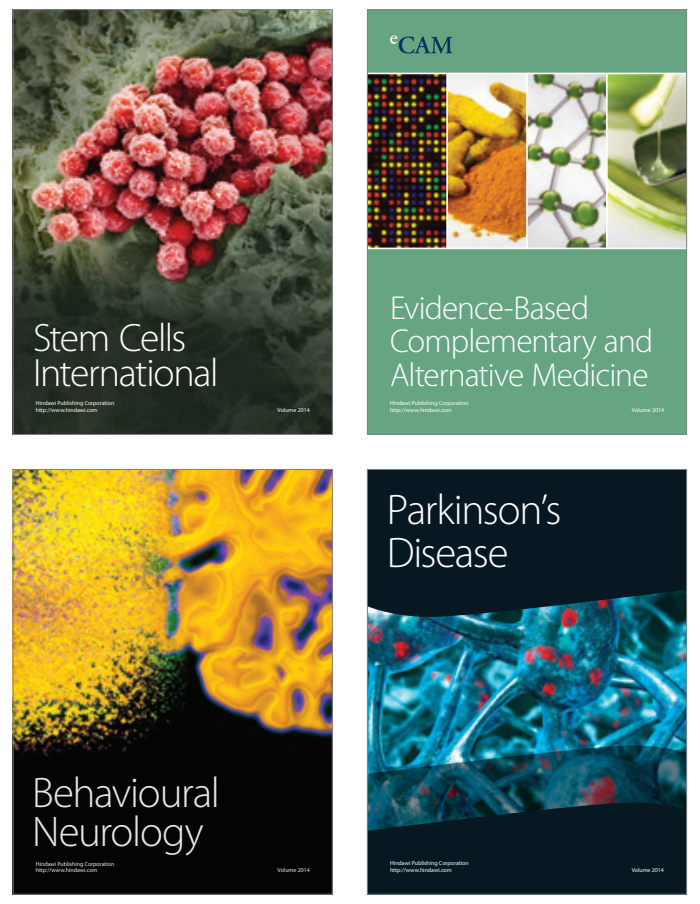
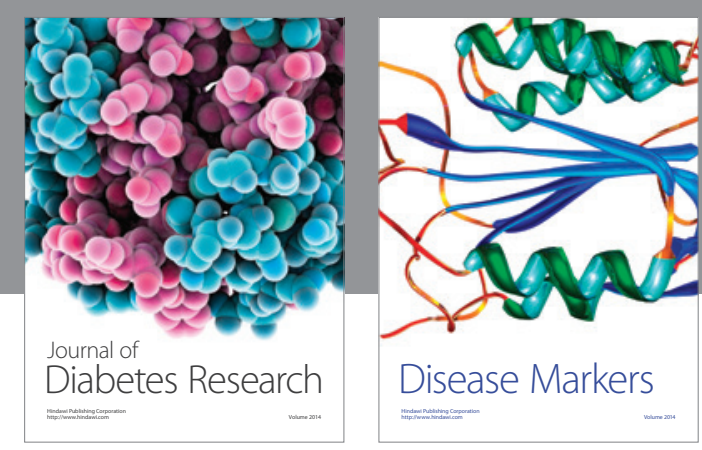

Disease Markers
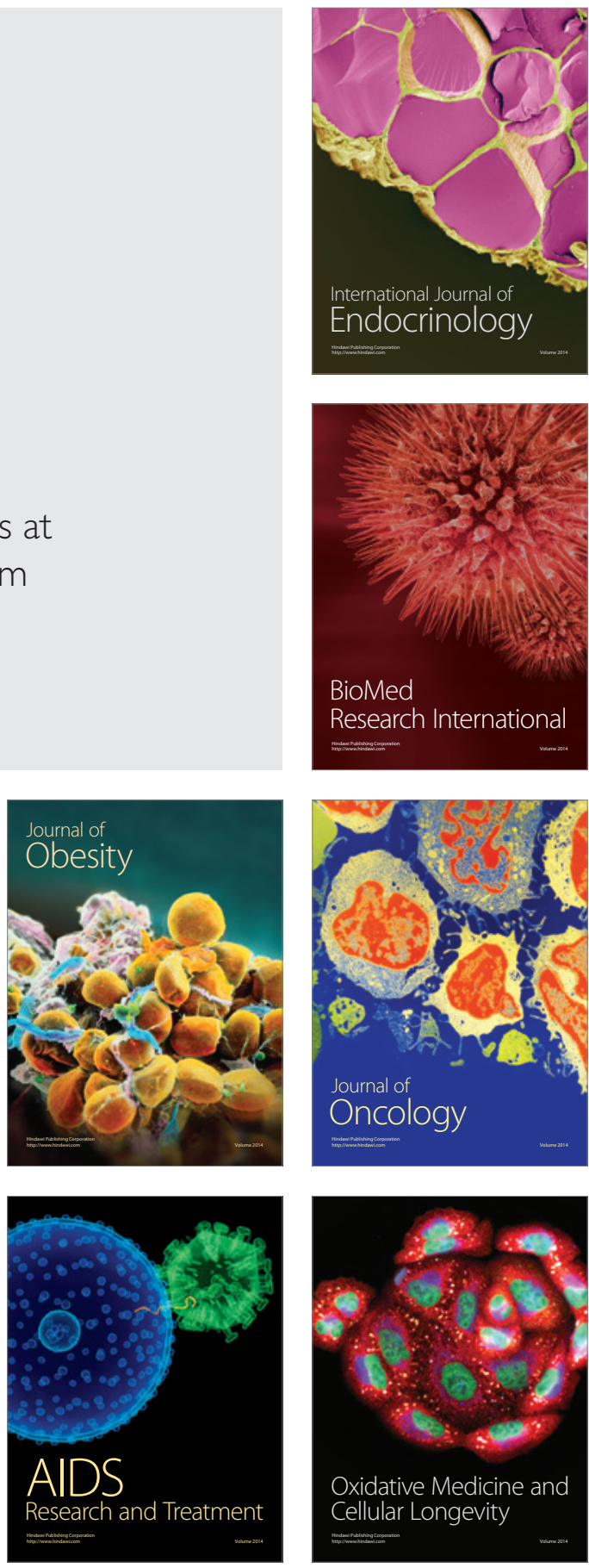